\title{
TREATMENT MANAGEMENT AND RESPONSE OF VOCAL CORD NODULES IN TERTIARY CARE HOSPITAL
}

\section{Medical Science}

Dr. Indranil Medical Officer (Supy), Swasthya Bhawan, , Kolkata, West Bengal. *Corresponding Khatua* Author

Dr. Alokendu bose Senior Resident, R. G. Kar Medical College And Hospital. Kolkata.

Dr. Indranath kundu

\section{Dr. Debarshi Jana} Hospital, Kolkata.

Young Scientist (DST), Institute Of Post-graduate Medical Education And Research, A.J.C. Bose Road, Kolkata-700020, West Bengal, India.

\section{ABSTRACT}

Background: Vocal fold nodules (VFNs), are localized, benign, superficial growths on the medial surface of the true vocal folds (TVFs) that are commonly believed to result from phonotrauma. Nodules are bilateral with a classic location at the junction of the anterior and middle third of the vocal fold (ie, the midpoint of the membranous vocal fold).

AIMS: Correlation between response of treatment (as evident by post-treatment and post follow up GRBAS score), in each group.

MATERIAL AND METHODS: Outpatient department and Indoor wards of Department of ENT and Head Neck surgery, R. G Kar Medical College. Patients attending ENT OPD of R G Kar Medical College during the Study period were the study population. Sample size was atleast 50 Patients.

RESULT: In group-A, the mean Pre Rx GRBAS (mean \pm s.d.) of the patients was $11.4118 \pm 2.0018$. In group-B, the mean Pre Rx GRBAS (mean \pm s.d.) of the patients was $11.1818 \pm 2.5794$.Distribution of mean Pre Rx GRBAS vs. group was not statistically significant $(\mathrm{p}=0.7499)$.

CONCLUSION: Vocal fold nodule is one of the most frequent benign laryngeal lesions, influencing the quality of life of those affected by them, primarily the vocal production. Despite being a well-established therapy in conjunction with surgery, speech therapy alone may also be effective in treating these lesions.

\section{KEYWORDS}

Treatment Management, Response, Vocal Cord Nodules

\section{INTRODUCTION}

Vocal cord nodules are bilateral, benign, and callous like growths of the mid portion of the membranous vocal folds. They are of variable size and characterised histologically by thickening of epithelium with a variable degree of inflammation in the underlying superficial lamina propria'. They characteristically produced hoarseness, discomfort and an unstable voice when speaking or singing ${ }^{2}$. The prevalence of nodules causing hoarseness in the general population in upto $23.4 \%$ of children, $0.5 \%$ to $1.3 \%$ of ENT Clinic attendances and $6 \%$ of phoniatric clinic attendance ${ }^{3}$. They can be caused by - Voice abuse (prolong shouting or singing above the individual's own range) but may also caused by infection, allergy, or acid reflux ${ }^{4}$. The definition of - vocal abuse is however subjective, although attempts have been made to define objective deviation ${ }^{5}$. The Diagnosis of nodules is by indirect Laryngoscopy and a Fibre Optic Laryngoscope(FOL). Vocal cord nodules can be surgically removed but may also be treated conservatively with medical and pharmacological treatment of infection, allergy, G.I. reflux, and vocal hygiene advice with voice rest and abuse reduction $10 \&$ vocal retraining. Surgical removal of the nodules includes exicision ${ }^{7}$ of nodules with Micro Surgical Instruments(steel)

\section{AIMS AND OBJECTIVE}

1. Determine age and sex wise occurrence of vocal nodules in this study population.

2. Correlation between response of treatment (as evident by posttreatment and post follow up GRBAS score), in each group.

\section{MATERIALAND METHODS}

Outpatient department and Indoor wards of Department of ENT and Head Neck surgery, R. G Kar Medical College from December 2017 to December 2019

\section{H. INCLUSION CRITERIA}

1. Patient with clinically bilateral vocal nodules, as diagnosed by rigid endoscopy and FOL examination.

2. Patients of both sexes and older than the pediatric age group ( $>=$ 12 years)

3. Patients without any past history of laryngeal surgery.

\section{EXCLUTION CRITERIA}

1. Patients younger than 12 years age.

2. Patient with other associated laryngeal lesion/tumors.

3. Patients with evidence of nasopharyngtis, oropharyngitis, hypopharyngitis.

\section{STATISTICALANALYSIS:}

For statistical analysis data were entered into a Microsoft excel spreadsheet and then analyzed by SPSS (version 25.0; SPSS Inc., Chicago, IL, USA) and GraphPad Prism version 5. Data had been summarized as mean and standard deviation for numerical variables and count and percentages for categorical variables. Two- sample ttests for a difference in mean involved independent samples or unpaired samples. Paired t-tests were a form of blocking and had greater power than unpaired tests. Unpaired proportions were compared by Chi-square test or Fischer's exact test, as appropriate. p-value $\leq 0.05$ was considered for statistically significant.

\section{RESULT AND ANALYSIS}

It was found that in group-A, $6(35.3 \%)$ patients had $\leq 30$ years of age, $8(47.1 \%)$ patients had $31-40$ years of age and $3(17.6 \%)$ patients had $41-50$ years of age. In group-B, $8(24.2 \%)$ patients had $\leq 30$ years of age, $18(54.5 \%)$ patients had $31-40$ years of age and $7(21.2 \%)$ patients had 41-50 years of age. Association of age vs. group was not statistically significant $(\mathrm{p}=0.7112)$. In group-A, $15(88.2 \%)$ patients were female and $2(11.8 \%)$ patients were male. In group-B, $19(57.6 \%)$ patients were female and $14(42.4 \%)$ patients were male. Association of sex vs. group was statistically significant $(\mathrm{p}=0.02769)$.

Our study showed that in group-A, the mean Pre Rx GRBAS (mean \pm s.d.) of the patients was $11.4118 \pm 2.0018$. In group-B, the mean Pre Rx GRBAS (mean \pm s.d.) of the patients was $11.1818 \pm$ 2.5794.Distribution of mean Pre Rx GRBAS vs. group was not statistically significant $(\mathrm{p}=0.7499)$. In group-A, the mean Post $\mathrm{Rx}$ GRBAS (mean \pm s.d.) of the patients was $1.3529 \pm 2.2063$.In group-B, the mean Post Rx GRBAS (mean \pm s.d.) of the patients was $2.4545 \pm$ 1.4809. Distribution of mean Post Rx GRBAS vs. group was statistically significant $(\mathrm{p}=0.0409)$.

We found that in group-A, the mean Ch1 GRBAS (mean \pm s.d.) of the patients was $10.0588 \pm 3.5084$. In group-B, the mean Ch1 GRBAS (mean \pm s.d.) of the patients was $8.7273 \pm 3.0236$.Distribution of mean 
Ch1 GRBAS vs. group was not statistically significant ( $\mathrm{p}=0.0648$ ). In group-A, the mean Post F/U GRBAS (mean \pm s.d.) of the patients was $1.4706 \pm 3.1448$.In group-B, the mean Post F/U GRBAS (mean \pm s.d.) of the patients was $2.7576 \pm 2.8508$. Distribution of mean Post $\mathrm{F} / \mathrm{U}$ GRBAS vs. group was not statistically significant $(\mathrm{p}=0.1507)$. In group-A, the mean $\mathrm{Ch} 2$ GRBAS (mean $\pm \mathrm{s}$.d.) of the patients was 9.9412 \pm 3.9126 . In group-B, the mean Ch2 GRBAS (mean \pm s.d.) of the patients was $8.4242 \pm 3.9531$.Distribution of mean Ch2 GRBAS vs. group was not statistically significant $(\mathrm{p}=0.2033)$.

\section{DISCUSSION}

Nakagawa $\mathrm{H}$ et al ${ }^{9}$ (2012) found that of those treated conservatively, 55 experienced complete resolutions after a mean of 5.1 months of follow-up from the outset, and 29 showed lesion shrinkage after a mean of 4.1 months of follow-up. Nodule that resolved with conservative therapy were more likely than those that remained unchanged or enlarged to occur in women, be smaller, and have a shorter duration of symptoms. They could not determine the superiority of voice therapy. At least $9.7 \%$ of vocal fold nodule might resolve without surgery. Conservative treatment should be considered as an option for selected patients with smaller and more recent-onset polyps.

It was found that in group-A, the mean Pre Rx GRBAS (mean \pm s.d.) of the patients was $11.4118 \pm 2.0018$.In group-B, the mean Pre $R x$ GRBAS (mean \pm s.d.) of the patients was $11.1818 \pm$ 2.5794.Distribution of mean Pre Rx GRBAS vs. group was not statistically significant $(\mathrm{p}=0.7499)$

We found that in group-A, the mean Post Rx GRBAS (mean \pm s.d.) of the patients was $1.3529 \pm 2.2063$.In group-B, the mean Post $\mathrm{Rx}$ GRBAS (mean \pm s.d.) of the patients was $2.4545 \pm 1.4809$. Distribution of mean Post Rx GRBAS vs. group was statistically significant $(\mathrm{p}=0.0409)$. In group-A, the mean Ch1 GRBAS (mean \pm s.d.) of the patients was $10.0588 \pm 3.5084$. In group-B, the mean Ch1 GRBAS (mean \pm s.d.) of the patients was $8.7273 \pm 3.0236$. Distribution of mean Ch1 GRBAS vs. group was not statistically significant ( $p=0.0648$ ).In group-A, the mean Post F/U GRBAS (mean \pm s.d.) of the patients was $1.4706 \pm 3.1448$.In group-B, the mean Post F/U GRBAS (mean \pm s.d.) of the patients was $2.7576 \pm 2.8508$. Distribution of mean Post F/U GRBAS vs. group was not statistically significant $(p=0.1507)$.In group-A, the mean Ch2 GRBAS (mean \pm s.d.) of the patients was $9.9412 \pm 3.9126$.In group-B, the mean Ch2 GRBAS (mean \pm s.d.) of the patients was $8.4242 \pm 3.9531$. Distribution of mean Ch2 GRBAS vs. group was not statistically significant $(\mathrm{p}=0.2033)$.

Hosoya $\mathrm{M}$ et al ${ }^{10}$ (2018) found that after 2 months, in the intervention group, the proportion of lesion resolution $(61.3 \%)$ was significantly greater than that in the control group $(26.3 \%)(\mathrm{P}<.001$, Fisher exact test). Their results clearly indicate that the quality and features of the education program could affect the outcome of the intervention. They found that a reinforced vocal hygiene education program increased the rate of the resolution of benign vocal fold polyps and nodules in a multicenter randomized clinical trial

We found that association of Pre Rx GRBAS vs. group was not statistically significant $(\mathrm{p}=0.3283)$. Association of Post Rx GRBAS vs. group was not statistically significant $(\mathrm{p}=0.2106)$.Post $\mathrm{F} / \mathrm{U}$ GRBAS 0 was higher 13(76.5\%) in group-A and Post F/U GRBAS 1 was higher $17(51.5 \%)$ in group-Association of Post F/U GRBAS vs. group was statistically significant $(\mathrm{p}=0.0004)$. In-group- $A$, the mean duration (mean \pm s.d.) of the patients was $5.9559 \pm 4.6723$.In group-B, the mean duration (mean $\pm \mathrm{s} . \mathrm{d}$.) of the patients was $6.8818 \pm 4.0286$.Distribution of mean duration vs. group was not statistically significant $(\mathrm{p}=0.4695)$.

de Vasconcelos D et al ${ }^{11}$ (2019) found that vocal fold nodule are one of the most frequent benign laryngeal lesions, impacting the quality of life of those affected by them, primarily the vocal production. Despite being a well-established therapy in conjunction with surgery, speech therapy alone may also be effective in treating these lesions. As such, otolaryngologists and speech therapists need updated bibliographic knowledge on the issue.

Vasconcelos DD et al ${ }^{12}(\mathbf{2 0 1 5})$ found that Speech therapy for the treatment of vocal fold polyps demonstrated effectiveness between $30 \%$ and $100 \%$ of the analyzed studies, with better results in small and recent polyps.

Şahin $M$ et al ${ }^{13}$ (2013) found that They obtained better voice parameters with improved GRBAS and SHE scores in patients with vocal cord nodules who underwent voice training and those with polyps who were operated, while these scores worsened following diagnostic phonosurgery in the intraepithelial group. In the initial examination, patients who are prediagnosed vocal cord nodules should have voice therapy as the first-line treatment modality and checked for the response to treatment.

Niebudek-Bogusz E et al ${ }^{14}(\mathbf{2 0 0 8})$ found that in pursuit of excellence in their profession, school teachers often ignore the most valuable tool in their possession - their voice. Teaching requires a high vocal demand, and consequently, teachers present a high risk of developing voice disorders during the course of their career. The prevalence of current voice disorders is significantly higher in teachers $(11 \%)$ when compared to non-teachers $(6.2 \%)$, as is the prevalence of voice disorders during teachers higher in teachers $(11 \%)$ when covs. $28.8 \%$ non- teachers). To evaluate teachers with dysphonia using voice analysis, objective analysis.

\section{CONCLUSION}

VF nodule may benefit from conservative management, especially female patients and those with small, recent-onset nodule. The majority of nodule that resolve do so within 8 months, which can assist clinical decision-making and counseling.

Voice training may significantly improve the postoperative voice quality of patients with vocal cord nodule and support rehabilitation.

Vocal fold nodule is one of the most frequent benign laryngeal lesions, influencing the quality of life of those affected by them, primarily the vocal production. Despite being a well-established therapy in conjunction with surgery, speech therapy alone may also be effective in treating these lesions.

Last, but not the least, patient compliance is extremely important for the result specially voice Quality.

Table: Distribution of mean Pre Rx GRBAS, Post Rx GRBAS and Post F/U GRBAS vs GROUP

\begin{tabular}{|c|c|c|c|c|c|c|c|c|}
\hline & & Number & Mean & SD & Minimum & Maximum & Median & p- value \\
\hline Pre Rx GRBAS & GROUP A & 17 & 11.4118 & 2.0018 & 8.0000 & 15.0000 & 11.0000 & 0.7499 \\
& GROUP B & 33 & 11.1818 & 2.5794 & 7.0000 & 15.0000 & 11.0000 & \\
\hline \multirow{2}{*}{ Post Rx GRBAS } & GROUP A & 17 & 1.3529 & 2.2063 & 0.0000 & 7.0000 & 1.0000 & 0.0409 \\
& GROUP B & 33 & 2.4545 & 1.4809 & 0.0000 & 7.0000 & 1.0000 & \\
\hline \multirow{2}{*}{ Post F/U GRBAS } & GROUP A & 17 & 1.4706 & 3.1448 & 0.0000 & 9.0000 & 0.0000 & 0.1507 \\
\cline { 2 - 9 } & GROUP B & 33 & 2.7576 & 2.8508 & 0.0000 & 9.0000 & 1.0000 & \\
\hline
\end{tabular}

\section{REFERENCE}

. Nagata K, Kurita S, Yasumoto S, Maeda T, Kawasaki H, Hirano M.Vocal fold polyps and nodules. A 10-year review of 1156 patients.Auris-Nasus- Larynx (Tokyo) 1983;Suppl 10:S27-35.Lacina (1972)

2. Lacina $\mathrm{O}$. The incidence of vocal fold nodules with singers [DasVorkommen von Stimmlippenknötchen bei den Sängern].Folia Phoniatrica1972;24:345- 54.HughMumer (1997)

3. Lacina O. The incidence of vocal fold nodules with singers [DasVorkommen von Stimmlippenknötchen bei den Sängern].Folia Phoniatrica1972;24:345- 54.HughMumer(1997).

4. Hugh-Munier CM, Scherer KR, Lehmann W, Scherer U. Coping strategies, personality, and voice quality in patients with vocal fold nodules and polyps. Journal of Voice 1997;11:452-61.
5. Xu JH, Ikeda Y, Komiyama S. Bio-feedback and the yawning breathpattern in voice therapy: a clinical trial. Auris-Nasus-Larynx (Tokyo)1991;18:67-77. Pedersen 1997Pedersen M. Biological development and the normal voice in puberty[thesis] Oulu: ActaUniversitatisOuluensis, 1997:17-24.Hocever (1997); Kuhn (1998)

6. Murry T, Woodson GE. A comparison of three methods for the management of vocal fold nodules. Journal of Voice 1992;6:271-6.

Fex B, Fex S, ShiromotoO,HiranoM. Acoustic analysis of functional dysphonia: before and after voice therapy (accent method). Journalof Voice 1994;8:163-7.

Wendler J, Seidner W. Results of surgical treatment of bones and polyps of the voca folds in adults [[Ergebnisse operative Behandlung von Knochen und Polypen der Stimmlipen [

. Nakagawa H, Miyamoto M, Kusuyama T, Mori Y, Fukuda H. Resolution of vocal fold polyps with conservative treatment. Journal of Voice. 2012 May 1;26(3):e107-10. 
10. Hosoya M, Kobayashi R, Ishii T, Senarita M, Kuroda H, Misawa H, Tanaka F, Takiguchi T, Tashiro M, Masuda S, Hashimoto S. Vocal hygiene education program reduces surgical interventions for benign vocal fold lesions: a randomized controlled trial. The Laryngoscope. 2018 Nov; 128(11):2593-9.

11. de Vasconcelos D, Gomes AD, de Araújo CM. Vocal Fold Polyps: Literature Review. International archives of otorhinolaryngology. $2019 \mathrm{Jan} ; 23(01): 116-24$

12. Vasconcelos DD, Gomes AO, Araújo CM. Effectiveness of speech therapy in the treatment of vocal fold polyps. Revista CEFAC. 2015 Dec;17(6):2009-17

13. Şahin M, Kirazlı T, Öztürk K, Ögüt MF. A presentation of a practical algorithm which can be used in the management of vocal cord nodules, polyps and intraepithelial neoplasias. The Turkish Journal of Ear Nose and Throat. 2013;23(2):96-103.

14. Niebudek-Bogusz E, Sznurowska-Przygocka B, Fiszer M, Kotyło P, Sinkiewicz A, Modrzewska M, Sliwinska-Kowalska M. The effectiveness of voice therapy for teachers with dysphonia. Folia Phoniatrica et Logopaedica. 2008;60(3):134-41. 